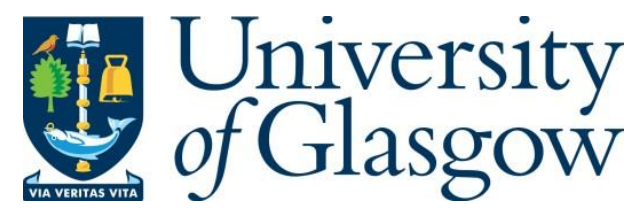

Barbopoulos, L. G. and Adra, S. (2016) The earnout structure matters: takeover premia and acquirer gains in earnout financed M\&As. International Review of Financial Analysis, 45, pp. 283-294.

There may be differences between this version and the published version. You are advised to consult the publisher's version if you wish to cite from it.

http://eprints.gla.ac.uk/149086/

Deposited on: 14 December 2017

Enlighten - Research publications by members of the University of Glasgow http://eprints.gla.ac.uk 


\title{
The Earnout Structure Matters: Takeover Premia and Acquirers Gains in Earnout Financed M\&As*
}

\author{
Leonidas G. Barbopoulos ${ }^{\mathrm{a}, \mathrm{x}}$
}

Samer Adrab

\begin{abstract}
In this article, based on both parametric and non-parametric methods, we provide a robust solution to the long-standing issue on how earnouts in corporate takeovers are structured and how their structure influences the takeover premia and the abnormal returns earned by acquirers. First, we quantify the effect of the terms of earnout contract (relative size and length) on the takeover premia. Second, we demonstrate how adverse selection considerations lead the merging firms to set the initial payment in an earnout financed deal at a level that is lower than, or equal to, the full deal payment in a comparable non-earnout financed deal. Lastly, we show that while acquirers in non-earnout financed deals experience negative abnormal returns from an increase in the takeover premia, this effect is neutralised in earnout financed deals.
\end{abstract}

Keywords: Earnout financing; Information asymmetry; Takeover premia; Abnormal returns; Propensity Score Matching; Rosenbaum-bounds.

JEL Classifications: G34.

\footnotetext{
${ }^{*}$ We are grateful to comments and suggestions offered by James Ang, Andrew Marshall, and Ian Smith. The authors are also grateful to comments and suggestions offered by the participants of the seminar series of the School of Economics \& Finance at the University of St. Andrews. Any remaining errors remain ours.

a University of St. Andrews, School of Economics \& Finance, Castlecliffe, The Scores, St Andrews, Fife, KY169AR; Tel: +44 (0) 133446 1955; Fax: +44 (0) 133446 2444; Email: leonidas.barbopoulos@st-andrews.ac.uk.

b Notre Dame University Lebanon, Faculty of Business Administration and Economics, Zouk Mosbeh, Lebanon, P.0 72, Tel: 009619208000; Email: sadra@ndu.edu.lb.

x Corresponding author.
} 


\section{Introduction}

Merging firms' managers tend to employ earnout contracts to finance Mergers and Acquisitions (M\&As) in which information asymmetry between the involved firms leads to substantial valuation disagreements over the deal's outcome. Such information asymmetry is highly relevant in private target acquisitions due to the low information disclosure requirements concerning private firms (Officer et al., 2009). ${ }^{1}$ In an earnout financed deal, the selling firm receives only a part of the deal's payment, i.e. the initial payment, at the time of the deal's announcement. Under this arrangement, the receipt of the deferred payment is conditional on the satisfaction of pre-specified performance related goals within a pre-determined period, i.e. the earnout period. ${ }^{2}$ The small number of shareholders, and hence the lack of separation between ownership and control in private firms, offer the private target's managers or owners an increased flexibility in negotiating unconventional forms of deal structuring like earnout financing (Kohers and Ang, 2000). Consequently, the reliance on earnout finacing has become a prominent characteristic of private target acquisitions in large takeover markets around the world like the United States (Datar et al., 2001; Cain et al., 2010) and the United Kingdom (Barbopoulos and Sudarsanam, 2012).

Earlier studies show that earnout financing, relative to single-payment financing, contributes to the achievement of many objectives to the benefit of both merging firms (Kohers and Ang, 2000; Barbopoulos and Sudarsanam, 2012). ${ }^{3}$ Nevertheless, several important issues remain to be investigated to enhance our understanding of how earnouts are structured and how their structure affects the valuations of merging firms. Specifically, it remains to be

\footnotetext{
1 The private target firms' managers or owners may have superior information about the values of the firms they manage, which gives rise to the adverse selection problem. The (un-observed) efforts of the merging firms' managers towards the maximisation of the outcome of the merger in the post-merger period give rise to the moral hazard problem.

2 The performance requirements may include specific thresholds related to the target firm's earnings, sales, and various profitability measures (Datar et al., 2001). However, the settlement of the deferred payment in a minority of earnouts can be linked to the satisfaction of a non-performance-based requirement such as the regulatory approval of a particular drug or the future licensing of a particular project (Cadman et al., 2014).

3 Evidence shows that such benefits are translated into higher short- and long-run abnormal returns for the acquirers shareholders (Barbopoulos and Sudarsanam, 2012) and higher offer-to-book values (premia) for the owners of the target firms (Kohers and Ang, 2000). The evidence that is reported by Kohers and Ang (2000) also suggests that 69\% of the private target shareholders ( 36 out of 52 cases) gain managerial privileges in the acquiring firm after the end of the earnout period.
} 
investigated: (a) how the earnout terms (relative earnout size and length of earnout contract) influence the premia offered in earnout financed deals, (b) how the deal value is divided between an initial and a deferred payment and, (c) how the abnormal returns earned by acquirers responds to the premia offered in both earnout and comparable non-earnout financed deals.

The answers to these questions are important for several reasons. First, given the heterogeneous nature of earnouts, the form of relationship between the earnout terms (i.e. size and length) and the premium offered in an earnout financed deal provides a useful guide regarding the association between the deal riskiness of success and the extent to which such risk is effectively shared between the merging partners. For example, in the presence of earnout financing, how much additional premium is required by the private target owners to accept the deferral of a larger part of the deal's payment, perhaps for an even longer period, than the already agreed ones? Second, the merging firms would acknowledge additional guidance on how to divide the deal value between the initial payment and the deferred one in an earnout financed acquisition. For example, should the acquiring firm offer a high initial payment to the private target owners in order to motivate them to enter the deal? Alternatively, should the acquiring firm ensure that the initial payment remains low relative to some threshold, despite the offering of high premium? Third, the acquiring firm's shareholders would favor a deeper understanding of how the market is processing information about the relatively high premia offered in earnout financed deals. Specifically, is the market interpreting the increase in the premia in earnout financed deals as a signal of overpayment, thus leading to lower acquirer abnormal returns? Alternatively, is the market interpreting such an increase in the premia as the result of a detailed contractual arrangement between the merging firms to address valuation disagreements without necessarily leading to the target overpayment but rather to a well-designed synergy-enhancing deal?

In this paper, given the extensive use of earnouts in the UK market for corporate control (Barbopoulos and Sudarsanam, 2012), we rely on a UK-based dataset that covers private target 
acquisitions in order to establish the link between the terms of earnouts and the difference between the takeover premia offered in earnout and comparable non-earnout financed deals. On the methodological front, we combine both non-parametric (matching) and parametric analyses to derive results that are robust to changes in the models' specifications and functional forms. Moreover, given the scarcity of publicly available private-target-specific information, and in addition to the use of a unique hand-collected dataset that covers the target's pre-acquisition performance, we employ the Rosenbaum (2002) bounds sensitivity analysis to measure the impact that a missing covariate should have on the odds of earnout use in the deal to alter our conclusions, as in Peel and Makepeace (2012). Several important and new results are uncovered.

First, we find that the heterogeneity in the structure of earnouts is significantly related to the premia offered in earnout financed deals, relative to non-earnout financed ones. More specifically, an additional $10 \%$ increase in the relative earnout size is associated with, on average, a $6.45 \%$ higher premium. ${ }^{4}$ Moreover, our results indicate that a 1 -month increase in the length of the earnout period is, on average, associated with a $0.6 \%$ higher premium. This evidence suggests that the private target owners are keen to ensure that the premia they are offered compensate them for: (a) sharing the post-merger integration risk with the acquirers, (b) offering their valuable services to facilitate the integration of the both firms during the earnout period and, (c) forgoing alternative valuable business and employment opportunities during this period. Overall, these results suggest that the magnitude of the target firm's compensation (premia) is not homogenous across all earnout financed deals but is rather highly sensitive to the terms of each earnout contract.

Second, while the previous studies have been primarily focused on examining the variation in the relative earnout size (Cain et al., 2011; Kohers and Ang, 2000), we show that, when designing an earnout contract, adverse selection considerations lead to a specific rule of thumb based on which the merging firms divide the deal payment between an initial and a deferred

\footnotetext{
${ }^{4}$ The relative earnout size is the maximum size of the deferred payment, relative to the full deal value.
} 
payment. Specifically, despite the offering of a higher premium in an earnout financed deal relative to a comparable non-earnout financed one, adverse selection considerations lead the acquiring firm to insist on setting the initial payment in an earnout financed deal at a level that is lower than, or equal to, the full deal payment in a comparable non-earnout financed deal. This finding contradicts the earlier univariate results derived by Kohers and Ang (2000) which indicate that even if the private target owners in an earnout financed deal do not receive the deferred payment, they still receive an initial payment that is higher than the full deal payment in a non-earnout financed deal (Kohers and Ang, 2000) (see their footnote 9, page 460).

We emphasize the relevance of carefully interpreting the results from earlier research within the univariate framework in which they were generated. Specifically, in their important contribution that highlights the determinants and wealth effects of earnout financing, Kohers and Ang (2000) provided a limited discussion of these findings and did not employ a parametric regression analysis or a matching-based approach to further verify their conclusions. We argue that their conclusion that the targets in earnout financed deals receive higher initial payments than the full payments in non-earnout financed deals is exposed to concerns whether earnout financing, instead of addressing information asymmetry problems, creates its own ones. In particular, the target firm's managers are incentivised to exaggerate the magnitude of valuation disagreements by limiting the information they are prepared to share with the acquirer. This aims to motivate the inclusion of the earnout in the deal's financing process, which leads the private target owners to receive an initial payment that exceeds the full payment they would otherwise receive had the earnout not included in the deal's financing process.

Our findings that are based on the multivariate analysis of comparable earnout and nonearnout financed deals suggest that the merging firms, and mostly the acquiring firms, are aware of such concerns. This, in turn, leads the acquirers to insist on adopting our previously mentioned rule of thumb as a condition to proceed with the earnout presence in the deal's financing process. Overall, this rule limits the target managers' incentives to exaggerate the extent of valuation disagreements in order to induce the use of the earnout as, otherwise, the 
initial payment they receive remains considerably lower than, or at most equal to, the full single-payment in a non-earnout financed deal.

Third, while the findings presented by earlier studies confirm that acquirers enjoy higher short-run abnormal returns from earnout financed, relative to non-earnout financed deals, we focus on the unexplored issues of: (a) the impact of the premia in earnout financed deals on the short-run abnormal returns gained by acquirers and, (b) the difference between the stock market's assessments of the premia offered in earnout and non-earnout financed deals. An increase in the premia in non-earnout financed deals, which are comparable to earnout financed ones, as identified via the Propensity Score Matching (PSM) method, should be interpreted as a signal of overpayment. This interpretation should lead to lower short-run abnormal returns for acquirers shareholders (Alexandridis et al., 2013; Mueller and Sirower, 2003). However, if earnout financing allows the acquirer to hedge against the risk of overpayment, the negative relationship between the premia and acquirers short-run abnormal returns should be limited to only non-earnout financed deals. Our results are consistent with this view: the negative relationship between the premia and the abnormal returns gained by acquirers is fully neutralised in earnout financed deals, as evidenced by the insignificant effect of the premia on the acquirers abnormal returns.

Finally, given the limited availability of private-target-specific information in the public domain, we interpret our results within the context of a sensitivity analysis that quantifies what impact a missing covariate should have on the likelihood of earnout financing presence to alter our conclusions. Our results that are insensitive to the effect of missing covariates are consistent with the argument that properly designed contractual arrangements (earnouts) contribute to the elimination of asymmetric information issues while enhancing the wealth effects of merging firms' shareholders, provided that the merging firms' managers are aware of the various types of risk-return trade-offs. 
We proceed as follows: Section 2 sets our hypotheses; Section 3 presents our methodology; Section 4 presents our dataset; Section 5 discusses the empirical findings; Section 6 provides a sensitivity analysis, and finally Section 7 concludes.

\section{Theoretical Framework and Hypotheses}

\subsection{The impact of earnout financing on the premium}

The game-theoretic model of Lukas et al. (2012) predicts an increase in the premium when an earnout is included in the deal. Several explanations can be offered to justify this result. First, as the target firm often operates as a subsidiary of the acquiring firm during the earnout period (Kohers and Ang, 2000), its performance and hence the likelihood of receiving the deferred payment are affected by the acquiring firm's overall business environment. As a result, the target firm demands a higher premium to be compensated for sharing the post-acquisition business risk with the acquirer. Second, the target owners can also be exposed to concerns related to possible disagreements with the acquiring firm regarding the accurate assessment of the target firm's performance, which reduces the likelihood of receiving the deferred payment at the end of the earnout period (Datar et al., 2001). Such concerns, in turn, may lead the private target owners to demand higher premia in exchange of accepting the presence of the earnout in the financing process of the deal.

Along these lines, Kohers and Ang (2000) show empirically that private targets in earnout financed deals are offered higher offer-to-book values than the targets in deals financed with single-payments. While such findings are based on a univariate analysis and obtained from analysing deals that are not necessarily comparable, they are likely to persist in our matched sample that consists of earnout and comparable non-earnout deals. Accordingly, our $\left(\mathrm{H}_{1}\right)$ is stated as follows: The takeover premia in earnout financed deals are, on average, higher than the premia offered in comparable non-earnout financed deals. 


\subsection{The relationship between the earnout terms and the premia}

A strong emphasis has been placed in the previous literature on the positive influence of both the riskiness of the target firm's business environment and the knowledge-base of its human capital on the relative earnout size (Cain et al., 2011; Datar et al., 2001). However, the relationship between the relative size of the earnout payment and the premium has only been theoretically investigated within the context of the game-theoretic option-based model of Lukas at al. (2012). The authors argue that the optimal investment decisions are determined by solving recursively an option pricing problem. The third stage of this problem refers to the settlement of the earnout payment, its second stage refers to the determination of the optimal level of co-operation by the target, and its first stage refers to the timing of the deal and its structure. At the third stage, given that the earnout can be treated as an option that is written on the underlying target firm's cash flows, the value of the option is identified. Based on this value, the target determines its optimal co-operation level. Finally, given this co-operation level, the acquirer determines the size of the earnout payment, the premium, and the timing of the deal.

When the riskiness of the target firm's cash flow increases, the probability of satisfying (by the target firm) the earnout's performance requirements also increases. This is analogous to the increase in the probability of exercising a stock option when the stock's riskiness increases. As a consequence, the target's managers or owners incentive of co-operating during the earnout period is reduced and hence the synergies of the acquisition are likely to decrease. To avoid this outcome, the earnout payment must increase to incentivise higher synergies. Moreover, the model shows that the initial payment is determined by a Nash Bargaining game in which the parties divide the value of the total payoff. Given that the initial payment is a function of the payoffs that are due to a high earnout payment, the initial payment also increases but such an increase is lower than the increase in the deferred payment. Consequently, there is a positive relationship between the relative earnout size and the premium, as they both reflect the degree of the acquisition riskiness of success. Accordingly, our $\left(\mathrm{H}_{2 \mathrm{a}}\right)$ is stated as follows: An increase in 
the relative size of the earnout payment is associated with an increase in the premium that is offered in an earnout financed deal.

The length of the earnout period, in turn, has the potential of being an influential determinant of the takeover premium. Given that the average earnout period exceeds 18 months, and by holding all the other factors constant, time-value-of-money considerations should lead the announced deal value in an earnout financed deal -which covers both the initial payment and the maximum value of the deferred payment- to exceed the lump-sum deal payment in a comparable non-earnout financed deal. Along similar lines, the model proposed by Lukas and Heinmann (2014) suggests that with a pre-determined earnout payment the target firm's owners are more inclined to accept earnout financing when the earnout period is relatively short in order to increase the value of their future cash flows.

Nevertheless, in addition to this consideration, the private target owners need to be rewarded for offering their business expertise to the acquirer to facilitate the merging firms' integration. Consequently, when offered a relatively long earnout period, the target owners are less likely to accept earnout financing unless the offered premium rewards them for both: (a) the business risk that they bear, and (b) the managerial skills that they offer to facilitate the merging firms' integrations. Indeed, the comparative statics resulting from the Lukas et al. (2012) theoretical model indicate that long earnout periods are associated with high deal payments. As a result, we empirically test the Lukas et al. (2012) theoretical predictions by examining the significance of the positive relationship between the earnout period (i.e. length of earnout contract) and the premium. Accordingly, our $\left(\mathrm{H}_{2 \mathrm{~b}}\right)$ is stated as follows: The longer the earnout period the higher the premium that is offered in an earnout financed deal.

\subsection{Adverse selection considerations}

Datar et al. (2001) argue that 'although earnouts may alleviate private information problems, these arrangements can also influence the incentives of the party managing the selling firm's assets post-acquisition' (p. 202). Hence, although earnouts are employed to address information 
asymmetry concerns, they have the potential to create their own ones, particularly when they are not efficiently designed. ${ }^{5}$ We argue that the relationship between the initial payment in an earnout financed deal and the full deal payment in a non-earnout financed deal is exposed to critical adverse selection concerns. The only findings we are aware of addressing this relationship are based on the univariate analysis of Kohers and Ang (2000), which shows that the target firms in earnout financed deals receive initial payments that are larger, on average, than the full deal payments received by targets in non-earnout financed deals. ${ }^{6}$

The adverse selection concern that emerges from these findings follows the argument that, as the target firm's managers or owners are aware that they will be offered a higher initial payment compared to the full deal payment in a non-earnout financed deal, they are likely to exaggerate the extent of valuation disagreements to a level that unnecessarily leads to the inclusion of earnout.

Contrary to the findings of Kohers and Ang (2000), which are based on: (a) univariate analysis and, (b) possibly a sample of non-comparable deals, adverse selection concerns should primarily incentivise the acquiring firm to insist on setting the initial payment at a level that is lower than, or equal to, the full deal payment in a comparable non-earnout financed deal. Such a contract design is likely to lead to an arrangement under which the target firm's owners are less incentivised to exaggerate the magnitude of valuation disagreements to unnecessarily induce the inclusion of the earnout. Otherwise, they would receive a lower initial payment than, or at most an equal payment to, the full deal payment in a comparable non-earnout financed deal. Accordingly, our $\left(\mathrm{H}_{3}\right)$ is stated as follows: The initial payment in an earnout financed deal is set to be, on average, at a lower level than, or equal to, the full deal payment in a comparable nonearnout financed deal.

\footnotetext{
5 The effects of adverse selection on corporate acquisitions design have been thoroughly investigated by Reuer and Ragozzino (2008).

6 The authors show that the average price-to-book value ratio in earnout financed deals, with the price excluding the deferred payment, exceeds the average price-to-book ratio in non-earnout financed deals $(3.7>2.2)$.
} 


\subsection{Earnout financing, takeover premia, and acquirers' abnormal returns}

The takeover premium has been employed in previous studies as a main determinant of the variation of the abnormal returns gained by acquirers (Hambrick and Hayward 1997; Alexandridis et al., 2013). Primarily, the market's assessment of an increase in the premium can be explained by either: (a) the synergy hypothesis whereby a high premium is interpreted as a reflection of high synergies to be realised from the merger (Antoniou et al., 2008; Díaz et al., 2009) or, (b) the over-investment hypothesis whereby a high premium is interpreted as a signal of managerial discretion and hubris that are leading the acquiring company's board to be engaged in a wasteful acquisition (Mueller and Sirower, 2003; Roll, 1986). ${ }^{7}$

The over-investment hypothesis can also explain the potential presence of high premia in private target deals (Cain et al., 2011; Capron and Shen, 2007; Datar et al., 2001; Kohers and Ang, 2000). Specifically, due to the limited availability of information about the private target's performance (Ball and Shivakumar, 2005), the acquirer is likely to overpay for the combination of assets and managerial skills as information asymmetry prevents the accurate evaluation of these factors on the potential synergies of the deal.

If earnout financing addresses a significant part of the information asymmetry problem, such a likelihood of overpayment should vary significantly between earnout and non-earnout financed deals. Specifically, for comparable deals, one would anticipate the market to negatively interpret the increase in the takeover premia that are offered in non-earnout financed deals in which earnout financing is likely to be included. Such a negative relationship should not persist when earnout financing is used, despite the offering of relatively high premia. This neutralisation of the negative effect of the premium on acquirers abnormal returns is due to the role of earnouts in addressing information asymmetry concerns. Following this discussion, our

\footnotetext{
7 The literature reports mixed results regarding the effect of the takeover premia on the abnormal returns gained by acquirers. Hambrick and Hayward (1997) and Mueller and Sirower (2003) find that premia have a negative effect on the acquirers gains. Alexandridis et al. (2013) find that the premium estimated using the piecewise regressions, based on the target's stock 52-week high, has a statistically and economically significant negative effect on the acquirers gains. Antoniou et al. (2008) find a positive effect of the premia on acquirers short-run gains. This effect is not reversed in the long-run. Díaz et al. (2009) document a non-linear relationship between the premia and acquirers gains: initial increases of the premia are treated as signals of synergies, leading to higher acquirers gains. Later increases in the premia are treated as signals of over-investment and hence acquirers are penalised by the market.
} 
$\left(\mathrm{H}_{4}\right)$ is stated as follows: The negative effect of the premia on the abnormal returns gained by acquirers in non-earnout financed deals is neutralised in comparable earnout financed deals.

\section{Methods}

In response to the growing popularity of matching analysis in empirical research, Ho et al. (2007) argue that matching in itself is not an estimation method: once a matched sample (containing the treated and control units) is established, an estimation procedure needs to be adopted to determine the factors influencing the treatment's outcome. The authors recommend that the researchers benefit from 'their decades of experience with parametric models to adjust the matched sample' (p. 213). Particularly, the matching on propensity scores is primarily used to balance the main covariates by simple $t$-tests on the matched sample (Rosenbaum and Rubin 1983). Then, parametric methods can be applied on the matched sample.

The previously discussed two-step approach provides results that are likely to be less dependent on the model's specification and functional form. First, regarding the model's specification, Ho et al. (2007) point out that the two-stage approach is doubly robust: either the matching model or the parametric model need to be correctly specified, but not necessarily both. Such an approach provides more flexibility to address our research question compared to the strict requirement of correct specification when parametric methods and matching are used separately. Second, regarding the functional form that is adopted in the model, King and Zeng (2005) show that, by dropping observations that have no matches, the researcher not only reduces the degree of model dependence, but also needs to add less emphasis on non-linear relations and interactions among the explanatory variables. In advocating the use of parametric regressions, Ho et al. (2007) do not recommend a change in the computations of the standard errors from the procedures typically used for the particular parametric method adopted.

Consequently, we first employ Propensity Score Matching (PSM) (as in Dehejia and Wahba, 2002; Behr and Heid, 2011; Peel and Makepeace, 2012) to create a matched sample that includes comparable earnout financed and non-earnout financed deals. Subsequently, we apply 
parametric estimation methods on the matched sample and proceed with the testing of the hypotheses developed in Section 2.

Based on the estimated probabilities from a Logistic model that includes a rich set of dichotomous and continuous covariates, earnout and non-earnout financed deals that have close estimated propensity scores are matched. Given that the number of earnout financed (treated) deals exceeds the number of non-earnout financed (control) deals in our sample, we rely on matching with replacement whereby a control observation can be used more than once, as in Dehejia and Wahba (2002). To benefit from the balancing offered by caliper matching (CM) while maintaining a considerable number of degrees of freedom to estimate the parametric models, we employ the highest possible matching caliper that leads to the balancing of the main covariates while maintaining the highest possible number of control observations. Then, we apply standard parametric analysis on the matched sample while controlling for the effects of the balanced variables, in addition to time and industry effects. ${ }^{8}$

An underlying assumption of the previously mentioned approach is that the main source of bias that the researcher is addressing is the one due to 'selection on observables' (Heckman and Robb, 1985). That is, it is assumed that the set of covariates that are balanced through the matching model and included in the parametric estimations include all the relevant factors. In a research field such as ours that involves private target acquisitions where target-specific information is rarely publicly available, the quantification of the effect of a missing covariate on the resulting conclusions remains critical. To accommodate for this concern, we employ the Rosenbaum-bounds sensitivity analysis via which the least biased estimation of propensities is obtained. Specifically, the Rosenbaum-bounds sensitivity method measures the impact that a missing covariate should have on the odds of earnout presence as the financing method in a given acquisition to alter our qualitative conclusions, as in Peel and Makepeace (2012). A more detailed discussion on the Rosenbaum-bounds method is offered in Section 6.

\footnotetext{
8 The matching and parametric analyses are conducted based on algorithms developed by Ho et al. (2006).
} 


\section{Data and Sample Features}

\subsection{The dataset}

Our sample covers acquisitions involving private target firms that are announced between January 1996 and December 2010 (inclusive) and recorded by the Securities Data Corporation (SDC) Thomson ONE database..$^{9}$ For a deal to remain in our sample, it must satisfy the following selection criteria: (a) the acquirer is a UK public firm listed in the London Stock Exchange and has a market value of at least $£ 1 \mathrm{~m}$ four weeks prior to the announcement of the deal; (b) the target is a UK or a non-UK private firm; (c) the transaction value should be at least $£ 1 \mathrm{~m}$, excluding fees; and (d) the acquirer should aim to control at least $50 \%$ of the target firm's assets after the transaction. Furthermore, to avoid the inseparable effects of multiple deals on acquirers gains, deals that announced by same acquirer within 5 days (i.e. the event window analysed) are excluded from our sample.

Following Officer's (2007) observation that 'acquisition multiple data from SDC is missing or inaccurate, and this data is critical to inferring the acquisition discount for unlisted targets' (p. 579), we search in the acquisition announcements from Nexis-UK and the InvestEgate Financial Press to obtain target-related measures that the acquiring firms have reported to their shareholders. We find that the acquirers are often report the target firm's pre-acquisition Audited Profits Before Taxes (PBT). We obtain 445 deals for which the PBT is available. After excluding deals in which the target has negative PBT (as it makes the calculation of the acquisition multiple economically inaccurate), 424 deals remain in our sample (299 earnout financed deals and 125 non-earnout financed deals). ${ }^{10}$

\subsection{Sample statistics}

Table 1 (Panel A) records the annual distribution of our sample according to the deal's payment type and method. The same table also records the annual distribution of our sampled deals in

\footnotetext{
9 The choice of the starting date follows from the observation of Faccio et al. (2006) that the SDC coverage of deals outside the United States becomes more accurate after 1996.

10 This sample represents $15.9 \%$ of the original sample of 2,797 observations. Such a percentage level is close to the level of $15.15 \%$ reported by Officer et al. (2009) who also deal with the inclusion of unlisted target-specific accounting measures in their sample.
} 
which: (a) the acquirer aims to control $100 \%$ of the target (FULL) and, (b) the target firm is a foreign firm (CBA). In our sample the earnout is the most frequent financing method $70.5 \%$ of the transactions) followed by acquisitions financed via single-payments in cash (CASH) (18.9\%).

(Insert Table 1 about here)

Table 1 (Panel B) reports the annual distribution of our sampled deals according to the target firm's industrial sector. Private firms based in the Consumer Products and Services (CPS) sector are more often involved in acquisitions covered in our sample $(24.5 \%)$, followed by private firms in the High-Technology (HT) sector with a share of $22.1 \%$. On the contrary, the target sectors with the lowest acquisition activity in our sample are the Energy and Power (EPW) with a share of $0.7 \%$ and the Real Estate (RST) with a share of $0.94 \%$. Moreover, consistent with earlier studies (i.e. Barbopoulos and Sudarsanam, 2012), our summary statistics suggest that the use of earnout financing is more likely in acquisitions involving targets from service-related sectors in which the value of the firm is highly sensitive to the knowledge, skill and creativity of only a few personnel. For example, earnouts are more frequently used in financing private target acquisitions in the Media and Entertainment (88\%), Healthcare (86\%) and the High Technology (82\%) sectors.

The absence of target market value in private target deals makes the estimation of the premia offered in such deals a relatively challenging task. Kohers and Ang (2001) present the offer price-to-book value of equity ratio as the best available premium measure. However, Ball and Shivakumar (2005) emphasize the low quality of financial data reported by private firms. As a result, we rely on the target performance measure that the acquirer -after accessing the target's records- has reported in the acquisition announcement, which is the target's positive Audited Profits Before Taxes (POSPBT). This allows for the calculation of the premium (PREMIUM), which is the outcome of the division of the deal payment, covering the initial payment and the deferred payment if the earnout is used, by the target's pre-acquisition profitability (PBT), as in Officer (2007) and Officer et al. (2009). 
Table 2 reports the mean and median of PREMIUM in addition to other key variables included in our analysis. Among the sample statistics recorded in Table 2, the mean (median) of PREMIUM in earnout financed deals is 39.27 (11.75), which is higher than the corresponding one offered in non-earnout financed ones (25.11 (8.82)). We also show that the acquirers engaging in earnout financed deals are younger and smaller, on average, than the ones engaged in single-payment deals. Such results are consistent with findings from previous research indicating that such acquirers are more vulnerable to the consequences of target valuation risk and hence are more likely to rely on deferred payments to maximise the likelihood of the deal's success (Barbopoulos and Sudarsanam, 2012; Kohers and Ang, 2000).11

(Insert Table 2 about here)

Regarding the terms of earnout contracts, we find that the mean (median) of the size of the earnout payment, as a percentage of the full deal value (REAS), of $36 \%(32 \%)$ is similar to the summary statistics reported by Barbopoulos and Sudarsanam (2012), 38\% (35\%). Regarding the length of the earnout contract (LENGTH), we report an average (median) value of 19.8 (19) months. This is lower than the one of 31 (23) month periods reported by Cain et al. (2011). Yet, it is close to the levels of 21.86 (22) months reported in Barbopoulos and Sudarsanam (2012).

\section{Results and Discussion}

\subsection{The balancing of the main covariates}

To ensure that the effect of selection bias on the comparative analysis of the premia and the abnormal returns gained by acquirers between earnout and non-earnout financed acquisitions is reduced, we employ the PSM method to match single-payment deals to those that have been financed with earnout. ${ }^{12}$ The PSM is a multi-step method consisting the estimation of propensity

\footnotetext{
11 The anonymous reviewer suggested that the young age of earnout acquirers in our sample might be driven by the high frequency of high technology (HT) firms. The firms in the HT sector are more likely to be young relative to companies in other sectors. In unreported estimations, we confirm the reviewer's prediction and find that the effect of the acquirer's age on the likelihood of earnout financing is driven by the presence of HT acquirers in the sample. These estimations are available from the authors upon request.

12 Unfortunately, matching directly on individual covariates becomes infeasible if the number of covariates is large. Consequently, we utilise the PSM approach along with the Rosenbaum-bounds method. This approach allows us to aggregate the impact of all covariates to derive a single score using a likelihood function.
} 
scores for earnout and non-earnout deals via a logistic regression and the matching of the earnout deals' propensity scores to the propensity scores of non-earnout financed deals. Our PSM aims to balance a large set of influential covariates with a caliper of 0.25 .

In addition to balancing the overall level of profitability level of the private targets between earnout and non-earnout financed deals on the matched sample, we also balance the percentage of the deal payment financed with stock (STOCK_PERC) in order to reflect the possible trade-off between stock and earnout financing, ${ }^{13}$ given that they have contingent payment properties (Chang 1998; Dataret al., 2001; Officer et al., 2009).14 To emphasize the importance of balancing the portions of domestic and cross-border acquisitions in the matched sample, we also include in our estimations a dichotomous variable (CBA) that is assigned the value of 1 if the target is a non-UK firm, and 0 otherwise. Noting that cultural and societal values can be a strong factor influencing the post-acquisition integration process especially in CBA, we also employ a Culture Index (CULT_IND) that allows us to balance the influence of cultural heterogeneity between the merging firms on the challenges faced during the integration process. This index is based on the graphical presentation presented by Radebaugh et al. (2006) which, in turn, is based on the traditional classification of country groups by cultural and societal values by Gray (1988). High values of CULT_IND indicate that the target firm belongs to a group of countries that focuses less on flexibility and more on uniformity in dealing with the accounting and organisational issues that might arise in a takeover, compared to the UK. Along these lines, the use of contractual tools that require precise measurement of the target performance, such as earnout financing, become less feasible. This variable is defined in Appendix 1. We also account for the acquirer experience in engaging in many acquisitions, as well as in assessing synergies, integrating targets, and evaluating the success of acquisitions in general, by controlling for the presence of frequent acquirers (FREQ) in our analysis. Moreover,

\footnotetext{
13 When the target firm's owners receive the acquiring firm's stock as part of the deal's payment, the value of this payment increases with the increase in the acquiring firm's stock price following the improvement in performance of the joint firm.

${ }_{14}$ We recognise that this measure is based on the deal value which is an outcome variable. Hence, in alternative estimations, instead of STOCK_PERC, we employ a dummy variable that is assigned the value of 1 if stock-financing is present, and 0 otherwise. The findings remain qualitatively similar to the ones reported.
} 
we balance the continuous variables representing the acquirer size (market value, MV) and acquirer age (AGE).

To ensure that the targets in the matched sample are similar in size with respect to their acquirers, we balance the dichotomous variable DUMMYRS, which is assigned the value of 1 if the relative size of the deal value to the acquirer market value exceeds $17 \%$, which is the third quartile in our initial SDC sample, and 0 otherwise. Given that the deal value is an output variable and hence it should not be included as a covariate in the matching procedure (Smith and Todd, 2005), the use of DUMMYRS that allows us to balance the percentages of relatively large targets in the matched sample between earnout and non-earnout financed deals without necessarily balancing the deal value. Hence, the PSM method ensures that the matched sample involves private target deals with targets being relatively similar to each other in terms of size and performance levels.

Table 3 records statistics on the balancing of the main covariates included in our analysis between the treated (earnout) and control group (non-earnout). This sample covers 299 earnout financed deals and 87 comparable non-earnout financed deals (386 deals in total). Evidently, all covariates are balanced between the two groups, which provides a strong indication of an accurate matching. These covariates, in addition to year and industry fixed effects, are included in our multivariate approach when we analyse of our matched sample.

$$
\text { (Insert Table } 3 \text { about here) }
$$

\subsection{Multivariate analysis of the premium}

Evidence recorded in Table 4 offers strong support to the argument that the presence of earnout financing, relative to its absence, leads to higher premia. Consistent with our hypothesis $\mathrm{H}_{1}$, and based on the interpretation of dummy variables in semi-logarithmic models that is offered by Kennedy (1981), the acquisition multiple in earnout financed deals is $31.11 \%$ higher 
than its equivalent in non-earnout counterparts. ${ }^{15}$ Consistent with $\mathrm{H}_{2 \mathrm{a}}$, Model 2 shows that the relative size of the deferred payment (REAS) has a significant positive association with the offered premium: a $10 \%$ increase in the relative size of the earnout payment is, on average, associated with $6.45 \%$ increase in the offered premium. In turn, as suggested by $\mathrm{H}_{2 b}$, the length of the earnout period (LENGTH) has a qualitatively similar effect on the premia. Specifically, a one-month increase in the length of the earnout period is associated with only $0.6 \%$ increase in the premium.

\section{(Insert Table 4 about here)}

Despite the arguments developed in earlier studies that the use of earnout financing is the initial step to establish a long term employer-employee relationship between the acquiring firm and the target's owners or managers (Datar et al., 2001), it appears that the merging firms are keen to separate the takeover considerations from the employment- and organisationalrelated ones. Specifically, our results add strong emphasis on the argument that the target firm's owners prefer the acquisition contract to explicitly recognise their compensation for bearing a significant portion of the post-acquisition integration risk and also for forgoing valuable alternative business or employment opportunities during the earnout period.

\subsection{The structure of the earnout payment}

To investigate the difference between the initial payment in earnout financed deals and the full deal payments in comparable non-earnout financed deals, we modify our approach adopted in Section 5.2 by introducing the following dependent variable:

$$
\text { INITIALDV }=\left\{\begin{array}{l}
\ln \left(\frac{\text { INITIALPMT }}{\text { POSPBT }}\right) \text { in earnout financed deals } \\
\ln \left(\frac{\mathrm{DV}}{\text { POSPBT }}\right) \text { in non }- \text { earnout financed deals }
\end{array}\right.
$$

Employing the INITIALDV as the dependent variable allows for the estimation of the premium based on the assumption that, in earnout financed deals, the deal payment is limited to

\footnotetext{
15 Based on the interpretation offered by Kennedy (1981), if the coefficient associated with a dummy variable in a semi logarithmic equation is $c$, the percentage impact of this variable on the outcome is $\exp (c-\operatorname{var}(c))-1$.
} 
the initial payment (INITIALPMT), i.e. the deferred payment is not delivered. The sign, magnitude, as well as significance of the coefficient associated with the dummy variable referring to the presence of the earnout (EA) in a regression over the matched sample, with INITIALDV being the dependent variable, allows us to examine the difference between the initial payments in earnout financed deals and the full deal payments in comparable non-earnout financed ones, relative to the target's pre-acquisition profitability.

Table 5 (Model 1) shows that, after controlling for several covariates over the matched sample, the initial payment in earnout financed deals is found to be significantly smaller than the full deal values in comparable non-earnout financed ones. This effect remains significant, yet at the $10 \%$ level, when time and industry effects are included in Model 2. Based on the interpretation of dummy variables in semi-logarithmic models that is offered by Kennedy (1981), the initial payment in an earnout financed deal is, on average, $21.10 \%$ lower than the full deal payment in a comparable non-earnout financed deal. Such findings lead to the nonrejection of $\mathrm{H}_{3}$ and highlight the importance of the hypothesised rule of thumb in dividing the deal payment between an initial payment and a deferred one.

\section{(Insert Table 5 about here)}

This finding provides a strong suggestion that the acquiring firms are aware of the adverse selection distortions that may arise from systematically committing to making significantly high immediate payments in earnout financed deals. Hence, despite the offer of high premia in earnout financed deals, the careful design of the initial and deferred payments to ensure the target firm's co-operation appears to be an important condition for those firms to proceed with the transaction.

\subsection{The determinants of abnormal returns earned by the acquirers' shareholders}

In Models 1 (Table 6) we investigate the determinants of the abnormal returns gained by acquirers by introducing the presence of earnout financing as an independent variable. Consistent with previous evidence presented by Barbopoulos and Sudarsanam (2012), our 
findings highlight the positive market response to the presence of earnout financing. Specifically, controlling for known determinants, ${ }^{16}$ earnout financed deals yield, on average, 2.2\% higher Cumulative Abnormal Returns (CAR) than non-earnout financed ones. ${ }^{17}$

To determine whether the market reacts differently to the premium level when the earnout is included compared to acquisitions in which the earnout is not included, we add PREMIUM and the product $(E A \times$ PREMIUM) as additional regressors in Model 2. Based on this specification, the coefficient associated with PREMIUM represents the market's sensitivity to the premia in non-earnout financed deals. In turn, the sum of the coefficients associated with PREMIUM and (EA $\times$ PREMIUM) represents the market assessment's sensitivity to the premia offered in earnout financed deals. According to our $\mathrm{H}_{4}$ the coefficient associated with PREMIUM is expected to be negative and the coefficient associated with (EA $\times$ PREMIUM) is expected to be positive, with an absolute value equal to that of the coefficient of PREMIUM.

(Insert Table 6 about here)

The results recorded in Model 2 indicate, as hypothesised in our $\mathrm{H}_{4}$, the two new relations that emerge between the variables PREMIUM and CAR. The first is negative, which is due to the absence of earnout financing. Specifically, as expected in non-earnout financed deals, an increase in the premium is interpreted negatively. However, the second relationship is positive with a magnitude being close in absolute value to the previous relation. ${ }^{18}$ The null hypothesis being the restriction that the coefficient associated with (EA $\times$ PREMIUM) is equal to the opposite value of the coefficient associated with PREMIUM is not rejected by a Wald test with a $p$-value of 0.77 . The sum of both coefficients is not statistically different than 0 , which indicates that the market's sensitivity to the premium in earnout financed deals is statistically

16 For industry and year effects, we include dummy variables that refer to each sector covered in the sample and each year, respectively. For cross-industry effects, we include a dummy variable that is assigned the value of 1 if the merging firms have different 2-digit SIC codes, and 0 otherwise.

17 As in Fuller, Netter, and Stegemoller (2002) and Faccio et al. (2006), we estimate the Cumulative Abnormal Returns (CAR) as the sum of the daily differences between the acquiring firm's stocks returns and the returns on a market index (the FT-ALL Share Index in particular) in the 5-day period $(-2,2)$ surrounding the acquisition's announcement date.

18 In alternative estimations, we include $\ln$ (PREMIUM) instead of PREMIUM as an independent variable. Our findings remain qualitatively similar to the ones reported when it comes to signs of the coefficients. However, the effects in these alternative estimations are not significant. Therefore, our findings indicate that the relation between the premia in earnout financed deals and non-earnout financed ones on one hand and the acquirer's CAR on another hand are linear. 
insignificant. Moreover, the distinction we present between the premium's influence on CAR in earnout and non-earnout financed deals explains the overall positive wealth effect of this financing method as it renders the coefficient of EA insignificant in the specification presented.

Overall, the insignificant relationship between the acquirers CAR to the level of the premia in earnout financed deals indicates that the offered premia in such deals, despite being relatively higher than the premia offered in comparable non-earnout financed deals, carries no implication on whether the target firm is overpaid. Rather, this premium is interpreted by the market as the outcome of detailed bargaining process that aims to ensure the completion of the deal by addressing the valuation disagreements between the merging partners.

\section{Sensitivity Analysis}

In the approach adopted in Section 5, we used matching analysis with the highest possible caliper to retain the highest number of comparable observations. Then, we applied parametric analysis on the resulting sample. In this Section, we add further emphasis on the validity of our results: (a) by using a smaller caliper to make the deals even more comparable, (b) by estimating the Average Treatment Effect on the Treated (ATT), which is the average difference in outcomes between the treated and the control observations on the matched sample and, (c) by applying a sensitivity analysis on the resulting $A T T$ to quantify the effect that a missing covariate should have on the presence of the treatment to alter our conclusions. Rosenbaum (2002) developed a sensitivity analysis that can accompany the use of PSM. In particular, while PSM remains a method that addresses 'selection on observables' (Heckman and Robb, 1985), the Rosenbaum sensitivity analysis answers the question: how strong a missing covariate would have to be, in terms of influencing the odds of assigning a treatment, in order to alter the qualitative conclusions of the study?

In the context of our analysis, this approach can be applied to our results related to the nonrejection of $\mathrm{H}_{1}$ and $\mathrm{H}_{3}$ in Section 5. Specifically, to what extent can we be confident, or how confident can we be, that: (a) the increase in premia in earnout financed deals relative to non- 
earnout financed deals and, (b) the argument that 'the initial payment in an earnout financed deal is lower than, or equal to, the full payment in a comparable non-earnout financed deal' can hold with the introduction of a missing covariate? These examinations are relevant given that a large amount of private-target-related information is not publicly available to be introduced to the analysis in the form of covariates that influence the use of earnout financing.

We write the odds of including an earnout in deal $i$, conditional on the set of empirical covariates $W$ that we employ in our analysis, as:

$$
\frac{P_{i}(E A=1 \mid W)}{1-P_{i}(E A=1 \mid W)}
$$

and for the deal $j$ that is matched to $i$ as:

$$
\frac{P_{j}(E A=1 \mid W)}{\left(1-P_{j}(E A=1 \mid W)\right)}
$$

Rosenbaum (2002) introduces the parameter $\Gamma$ in the following relation:

$$
\frac{1}{\Gamma} \leq \frac{\frac{P_{i}(E A=1 \mid W)}{1-P_{i}(E A=1 \mid W)}}{\frac{P_{j}(E A=1 \mid W)}{\left(1-P_{j}(E A=1 \mid W)\right)}} \leq \Gamma
$$

Mainly, when $\Gamma=1$, the assignment of earnout between the two matched units is equivalent to a random assignment. As the value of $\Gamma$ increases, the assignment of the earnout no longer remains a random procedure. As shown by Rosenbaum (2002), the fraction of odds can be written as:

$$
\frac{\frac{P_{i}(E A=1 \mid W)}{1-P_{i}(E A=1 \mid W)}}{\frac{P_{j}(E A=1 \mid W)}{\left(1-P_{j}(E A=1 \mid W)\right)}}=\frac{\exp \left(k(W)+\gamma u_{i}\right)}{\exp \left(k(W)+\gamma u_{j}\right)}=\exp \left\{\gamma\left(u_{i}-u_{j}\right\}\right.
$$

$\gamma \geq 0$ where $k(W)$ represents the effects of the observed covariates. $u_{i}$ and $u_{j}$ are the unobserved covariates influencing the presence of earnout financing in deals $i$ and $j$ respectively. $\gamma$ represents the influence of these covariates on the decision to include the earnout. Normalising $u=u_{i}-u_{j}$ between 0 and $1, \Gamma$ can be written as $\Gamma=e^{\gamma}$ and a straight forward interpretation is that the matched deals may differ in their odds of including an earnout 
by at most $\Gamma$ (Rosenbaum 2002). Along these lines, $\gamma$ can be interpreted as the coefficient associated with the missing covariate $u$ in a Logistic regression.

Our results reported in Table 7, based on PSM with a caliper of 0.01 and the Logistic model specification as in Table 3, present inferences that are in line with conclusions of Section 5.19 These inferences are very insensitive to the effect of a missing covariate. In particular, our ATT estimate of $\ln (\mathrm{PREMIUM})$ is $47.23 \%$ and is significant at the $1 \%$ level. $^{20}$ In turn, the $A T T$ estimate of the impact of earnout on INITIALDV is insignificant. Hence, the initial payment in an earnout financed deal is not statistically different than the full deal payment in a comparable non-earnout financed one. Based on $\Gamma$ levels of the Rosenbaum (2002) sensitivity analysis, a missing covariate need to increase the odds of one of two matched deals, including the earnout relative to the control from the non-earnout group, by a factor of 1.5 to 2 in order to: (a) make the impact of the earnout's presence on the premium statistically insignificant and, (b) make the difference between the initial payment in an earnout financed deal and the full payment in a non-earnout financed one positive and statistically significant. ${ }^{21}$

(Insert Table 7 about here)

The $\Gamma$ levels of 1.5 and 2 that we report are close, for instance, to the level of 1.55 that is reported in the Peel and Makepeace (2012) study of the premium received by accounting auditors. Furthermore, in our Logistic model, these effects are equivalent to a required reduction in the portion of the deal that is financed by stocks from $57 \%$ and $34 \%$, respectively, to 0 , i.e. to employ full cash financing in order to alter our qualitative conclusions. These reductions reflect strong economic effects given that the standard deviation of the percentage of the deal financed by stocks is $23 \%$. Following the emphasis of Core $(2010)$ that results in empirical accounting and finance research are not frequently supported by sensitivity analyses,

\footnotetext{
19 The key covariates are balanced on the resulting matched sample as in Table 3. This matched sample covers 135 earnout financed deal and 64 non-earnout financed ones.

20 Abadie and Imbens (2008) show that estimators resulting from bootstrap procedures are not valid even under the simple conditions of a single continuous covariate and an unbiased $N^{1 / 2}$ normally distributed estimator. The results of the Abadie and Imbens (2008) simulation show that the variance estimator they developed (Abadie and Imbens, 2006) tends to perform well even with small samples. Consequently, in testing the null hypothesis of zero ATT, the Abadie and Imbens (2006) standard errors are employed in the $t$-tests and reported with the results.

21 These results are based on the Wilcoxon Rank Sum Test at each $\Gamma$ level.
} 
our results provide a clear indication that our conclusions are relatively insensitive to the effect of a missing covariate on the odds of the earnout's presence in the financing process of the deal.

\section{Conclusion}

By employing an exclusive sample of UK private target acquisitions, this article presents the first empirical contribution that: (a) defines the relationship between the terms of the earnout contract (relative earnout size and length of earnout contract) and the premia offered in private target deals that are financed with earnouts and, (b) accounts for the earnout impact on the relationship between the premia and the abnormal returns gained by acquirers. Specifically, we show that relatively large deferred payments and longer earnout periods are associated with higher takeover premia in earnout financed deals, compared to the takeover premia offered in comparable single-payment (non-earnout) deals. This suggests that the target firm's owners in an earnout financed acquisition are compensated for sharing the post-acquisition integration risk with the acquiring firm by being offered relatively higher premia. In addition, we present evidence regarding the presence of a specific rule of thumb that governs the relationship between the initial payment in an earnout financed deal and full payment in a comparable nonearnout financed one: the initial payment in the former group is set to be, on average, at a lower level than, or equal to, the full deal payment in the latter group. This suggests that the acquiring firms are aware of the ramifications of making high immediate payments to their targets as such high payments may distort the incentives of the private target's owners (often managers) in sharing information with the acquirer during the merger evaluation period.

Moreover, we investigate the abnormal returns gained by acquirers in deals that are financed with earnouts versus single-payments (non-earnouts). We find that an increase in the premia in non-earnout financed deals is interpreted as a signal of overpayment. On the contrary, given that earnout contracts are employed to address information asymmetry issues that may destroy the acquisition's accurate evaluation, the relatively high premium in an earnout financed deal is not interpreted by the market as a signal of overpayment. This result is 
obtainable provided that the receipt of a significant part of the premium is contingent upon the target firm satisfying a large set of pre-determined post-acquisition performance requirements and perhaps, any valuation error is likely to be corrected at a future time.

Given the limited availability of private target-specific information in the public domain, we rely on the Rosenbaum (2002) sensitivity analysis to quantify what the effect that a missing covariate should be on the odds of earnout presence to alter our qualitative conclusions. We find that our results are not sensitive to the impact of an omitted or unobserved covariate and hence, our conclusions are likely to be consistent in other specifications including a richer set of covariates.

Finally, it is worth noting that our estimates of the earnout's wealth effects which are derived from a UK-based dataset cannot be generalized to other contexts without a detailed cross-country empirical investigation. For instance, Lukas and Heimann (2014) find that wealth effects of earnout financing relative to lump-sum payments are larger in Germany compared to the United States. The authors present this result as evidence that the concentrated ownership of German firms relative to the US firms reduces the transaction and monitoring costs of earnout contracts in Germany and consequently increases the earnout's wealth effects. Furthermore, the authors find that non-earnout financed deals are not necessarily detrimental to the acquiring firms' shareholders, as evidenced by their positive significant abnormal returns. Therefore, before suggesting that our results can be generalized in non-UK contexts, the methodology adopted in this article, via which we combine matching and parametric methods using firm-specific performance data, needs to be applied in a larger cross-country investigation of the wealth effects of payment methods in M\&A.

Overall, our paper adds further emphasis on the usefulness of earnout financing in addressing information asymmetry in M\&As and in providing a contextual framework that allows both the acquiring and the target firms to reap additional benefits from the M\&A transaction. Finally, the combination of both parametric and non-parametric methods offers a robust approach of designing our research strategy in this article, which allows us to gain 
enough confidence regarding the procedures one should follow when designing earnouts, in addition to evaluating the effects of earnout financing on the takeover premia and the abnormal returns gained by acquirers. 


\section{References}

Abadie, A., Imbens, G.W., 2008. On the failure of the bootstrap for matching estimators. Econometrica 76, 1537-1557. doi:10.3982/ECTA6474

Abadie, A., Imbens, G.W., 2006. Large sample properties of matching estimators for average treatment effects. Econometrica 74, 235-267. doi:10.1111/j.1468-0262.2006.00655.x

Alexandridis, G., Fuller, K.P., Terhaar, L., Travlos, N.G., 2013. Deal size, acquisition premia and shareholder gains. Journal of Corporate Finance. 20, 1-13. doi:10.1016/j.jcorpfin.2012.10.006

Antoniou, A., Arbour, P., Zhao, H., 2008. How much is too much: are merger premiums too high? European Financial Management. 14, 268-287. doi:10.1111/j.1468-036X.2007.00404.x

Ball, R., Shivakumar, L., 2005. Earnings quality in UK private firms: comparative loss recognition timeliness. Journal of Accounting and Economics. 39, 83-128.

Barbopoulos, L., Sudarsanam, S., 2012. Determinants of earnout as acquisition payment currency and bidder's value gains. Journal of Banking and Finance. 36, 678-694. doi:10.1016/j.jbankfin.2011.10.007

Cadman, B., Carrizosa, R., Faurel, L., 2014. Economic determinants and information environment effects of earnouts: new insights from SFAS 141(R). Journal of Accounting Research. 52, 37-74. doi:10.1111/1475-679X.12036

Cain, M.D., Denis, D.J., Denis, D.K., 2011. Earnouts: a study of financial contracting in acquisition agreements. Journal of Accounting and Economics. 51, 151-170. doi:10.1016/j.jacceco.2010.05.001

Capron, L., Shen, J.-C., 2007. Acquisitions of private vs. public firms: Private information, target selection, and acquirer returns. Strategic Management Journal. 28, 891-911. doi:10.1002/smj.612

Chang, S., 1998. Takeovers of Privately Held Targets, Methods of Payment, and Bidder Returns. Journal of Finance 53, 773-784. doi:10.1111/0022-1082.315138

Core, J., 2010. Discussion of chief executive officer equity incentives and accounting irregularities. Journal of Accounting Research 48, 273-287. doi:10.1111/j.1475679X.2010.00367.x

Datar, S., Frankel, R., Wolfson, M., 2001. Earnouts: the effects of adverse selection and agency costs on acquisition techniques. Journal of Law and Economic Organization. 17, 201-238. doi:10.1093/jleo/17.1.201

Dehejia, R.H., Wahba, S., 2002. Propensity score matching methods for nonexperimental causal studies. Review of Economics and Statistics. 84, 151-161. doi:10.1162/003465302317331982

Díaz, K.B.D., Azofra, S.S., Gutiérrez, C.L., 2009. Are M\&A premiums too high? analysis of a quadratic relationship between premiums and returns. quarterly Journal of Finance and Accounting. 48, 5-21.

Faccio, M., McConnell, J.J., Stolin, D., 2006. Returns to acquirers of listed and unlisted targets. Journal of Financial and Quantitative Analysis. 41, 197-220.

Fuller, K., Netter, J., Stegemoller, M., 2002. What do returns to acquiring firms tell us? evidence from firms that make many acquisitions. Journal of Finance 57, 1763-1793. doi:10.1111/1540-6261.00477

Gray, S.J., 1988. Towards a theory of cultural influence on the development of accounting systems internationally. Abacus 24, 1-15. doi:10.1111/j.1467-6281.1988.tb00200.x

Hambrick, M., Hayward, D., 1997. Explaining the premiums paid for large acquisitions: evidence of CEO hubris. Administrative Science Quarterly. 42, 103-127.

Heckman, J.J., Robb, R., 1985. Alternative methods for evaluating the impact of interventions: an overview. Journal of Econometrics. 30, 239-267.

Ho, D., Imai, K., King, G., Stuart, E., 2006. Matchit: nonparametric preprocessing for parametric casual inference. 
Ho, D.E., Imai, K., King, G., Stuart, E.A., 2007. Matching as nonparametric preprocessing for reducing model dependence in parametric causal inference. Political Analysis. 15, 199236. doi:10.1093/pan/mpl013

Kennedy, P., 1981. Estimation with correctly interpreted dummy variables in semilogarithmic equations. American Economic Review. 71, 801.

King, G., Zeng, L., 2005. The dangers of extreme counterfactuals. Political Analysis. 14, 131-159. doi:10.1093/pan/mpj004

Kohers, N., Ang, J., 2001. The take-over market for privately held companies: the US experience. Cambridge Journal of Economics. 25, 723-748. doi:10.1093/cje/25.6.723

Kohers, N., Ang, J., 2000. Earnouts in mergers: agreeing to disagree and agreeing to stay. Journal of Business. 73, 445-476.

Lukas, E., Reuer, J.J., Welling, A., 2012. Earnouts in mergers and acquisitions: a game-theoretic option pricing approach. European Journal of Operation Research. 223, 256-263. doi:10.1016/j.ejor.2012.05.017

Lukas, E. Heimann, C., 2014. Technological-induced information asymmetry, M\&As and earnouts: stockmarket evidence from Germany. 24, 481-493

Mueller, D.C., Sirower, M.L., 2003. The causes of mergers: tests based on the gains to acquiring firms' shareholders and the size of premia. Managerial and Decision Economics. 24, 373391. doi:10.1002/mde.1103

Officer, M.S., 2007. The price of corporate liquidity: acquisition discounts for unlisted targets. Journal of Financial Economics. 83, 571-598. doi:10.1016/j.jfineco.2006.01.004

Officer, M.S., Poulsen, A.B., Stegemoller, M., 2009. Target-firm information asymmetry and acquirer returns. Review of Finance. 13, 467-493. doi:10.1093/rof/rfn017

Peel, M.J., Makepeace, G.H., 2012. Differential audit quality, propensity score matching and rosenbaum bounds for confounding variables. Journal of Business Finance and Accounting. 39, 606-648. doi:10.1111/j.1468-5957.2012.02287.x

Radebaugh, L., Gray, S., Black, E., 2006. International accounting and multinational enterprises. Wiley Blackwell, New York, NY.

Ragozzino, R., Reuer, J.J., 2009. Contingent earnouts in acquisitions of privately held targets. Journal of Management. 35, 857-879. doi:10.1177/0149206308328503

Reuer, J.J., Ragozzino, R., 2008. Adverse selection and M\&A design: The roles of alliances and IPOs. Journal of Economic Behavior and Organization. 66, 195-212.

Roll, R., 1986. The hubris hypothesis of corporate takeovers. Journal of Business. 59, 197-216.

Rosenbaum, P., 2002. Observational studies. Sringer Series in Statistics.

Rosenbaum, P., Rubin, D., 1983. The central role of the propensity score in observational studies for causal effects. Biometrika 70, 41-55.

Smith, J., Todd, P., 2005. Does matching overcome LaLonde's critique of nonexperimental estimators? Journal of Econometrics. 125, 305-353. doi:10.1016/j.jeconom.2004.04.011

White, H., 1980. A heteroskedasticity-consistent covariance matrix estimator and a direct test for heteroskedasticity. Econometrica 3, 216-227. 


\section{Appendix 1 - Variable definitions}

\begin{tabular}{|c|c|c|}
\hline $\begin{array}{r}\text { Variable } \\
\text { (Acronym) }\end{array}$ & Description & Source \\
\hline Acquirer's Age (AGE) & $\begin{array}{l}\text { The number of days between the acquirer's listing in Datastream } \\
\text { and the announcement date. }\end{array}$ & Datastream \\
\hline $\begin{array}{r}\text { Acquirer's Market-to- } \\
\text { Book Value } \\
\text { (ACQMTBV) } \\
\end{array}$ & $\begin{array}{l}\text { The market value of the acquirer at four weeks before the } \\
\text { acquisition, divided by its book value of equity from the most } \\
\text { recent accounting statement prior to the bid announcement. }\end{array}$ & Datastream \\
\hline $\begin{array}{r}\text { Audited Profits Before } \\
\text { Taxes (PBT) }\end{array}$ & $\begin{array}{l}\text { The target's Audited Profits Before Taxes for the financial year } \\
\text { preceding the acquisition as covered in the acquisition } \\
\text { announcement. }\end{array}$ & InvestEgate + Nexis-UK \\
\hline $\begin{array}{r}\text { Cash Financed } \\
\text { Transactions (CASH) }\end{array}$ & $\begin{array}{l}\text { Dummy }=1 \text { if the consideration is } 100 \% \text { financed with cash and } 0 \\
\text { otherwise. }\end{array}$ & SDC \\
\hline $\begin{array}{r}\text { Cross-Border } \\
\text { Acquisition (CBA) }\end{array}$ & $\begin{array}{l}\text { Dummy }=1 \text { when the transaction includes a UK acquirer and non- } \\
\text { UK target and = } 0 \text { when the target is a UK firm [= DOM]. }\end{array}$ & SDC \\
\hline $\begin{array}{l}\text { Culture Index } \\
\text { (CULT_INDEX) }\end{array}$ & $\begin{array}{l}\text { An index that ranks the countries in which the targets are listed } \\
\text { from the most flexible to the least flexible, and from the most } \\
\text { transparent to the least transparent, in dealing with accounting } \\
\text { and organisational challenges. It takes the following values: } \\
\text { 1. The country of the firm acquired belongs to the Anglo-American } \\
\text { group. The countries included are: United Kingdom, Canada, the } \\
\text { Republic of Ireland, United States, New Zealand, South Africa and } \\
\text { Australia. } \\
\text { 2. The country of the firm acquired belongs to the Nordic group. } \\
\text { The countries included are: Sweden, Denmark, Finland, Norway } \\
\text { and Netherlands. } \\
\text { 3. The country of the firm acquired belongs to the Asian-Colonial } \\
\text { group. The countries included in this case are: Hong Kong and } \\
\text { Singapore. } \\
\text { 4. The country of the firm acquired belongs to the Germanic group. } \\
\text { The countries included are: Germany, Austria, Israel and } \\
\text { Switzerland. } \\
\text { 5. The country of the firm belongs to the remaining groups. The } \\
\text { underlying assumption in this case is that once high differences in } \\
\text { the degree of flexibility are reached, the ordering of the accounting } \\
\text { systems becomes less relevant. }\end{array}$ & $\begin{array}{l}\text { SDC + The classification provided } \\
\text { by Gray (1988) in which he uses } \\
\text { cultural and societal values as } \\
\text { primary characteristics for } \\
\text { grouping families of countries. The } \\
\text { ranking of the flexibility of these } \\
\text { groups' accounting systems is } \\
\text { represented graphically by } \\
\text { Radebaugh et al. (2006). }\end{array}$ \\
\hline $\begin{array}{r}\text { Cumulative Abnormal } \\
\text { Returns (CAR) } \\
\end{array}$ & $\begin{array}{l}\text { The sum of the acquirer's abnormal returns in the 5-day window } \\
\text { surrounding the announcement }\end{array}$ & Datastream \\
\hline Deal Value (DV) & $\begin{array}{l}\text { Reported deal value, in millions of pounds. This value covers the } \\
\text { initial payment and the maximum value of the reported deferred } \\
\text { payment when an earnout is included }\end{array}$ & SDC \\
\hline Earnout (EA) & $\begin{array}{l}\text { Dummy }=1 \text { when the consideration includes an earnout [EA] and } 0 \\
\text { otherwise [NEA] }\end{array}$ & SDC \\
\hline $\begin{array}{r}\begin{array}{r}\text { Earnout Value } \\
\text { (EASIZE) }\end{array} \\
\end{array}$ & Value of the reported maximum earnout size, in million pounds. & SDC \\
\hline $\begin{array}{r}\text { Frequent Bidder } \\
\text { (FREQ) }\end{array}$ & $\begin{array}{l}\text { Dummy }=1 \text { when the acquirer is classified as a frequent bidder and } \\
0 \text { otherwise. The acquirers who bid more than the third quartile of } \\
\text { bid counts per acquirer in the SDC sample of } 2797 \text { discussed in } \\
\text { Section } 2 \text { ( } 9 \text { bids) are classified as frequent bidders. }\end{array}$ & SDC \\
\hline $\begin{array}{r}\text { High Relative Size of the } \\
\text { Deal } \\
\text { (DUMMYRS) }\end{array}$ & $\begin{array}{l}\text { Dummy=1 if the deal value relative to the market value of the } \\
\text { acquirer's market value is higher than the third quartile of } 17 \% \text {. }\end{array}$ & SDC \\
\hline $\begin{array}{r}\text { Initial Payment in } \\
\text { Earnout Financed Deals } \\
\text { (INITIALPMT) }\end{array}$ & The value of the initial payment in earnout financed deals. & SDC \\
\hline $\begin{array}{r}\text { Length of the Earnout } \\
\text { Period } \\
\text { (LENGTH) }\end{array}$ & $\begin{array}{l}\text { The length of the earnout period in months as present in the } \\
\text { acquisition announcement. When no earnout is present, this } \\
\text { variable takes the value of } 0 \text {. When an earnout is present and the } \\
\text { acquisition announcement refers to the auditing of the target's } \\
\text { account without mentioning the length of the Earnout period we } \\
\text { give this variable a value of } 1 \text {. }\end{array}$ & Nexis-UK + InvestEgate \\
\hline $\begin{array}{l}\text { Market Value of the } \\
\text { Acquirer's Equity (MV) }\end{array}$ & $\begin{array}{l}\text { Acquirer's market value of equity at four weeks prior to bid } \\
\text { announcement, in millions of pounds. We also employ the natural } \\
\text { logarithm of this variable. }\end{array}$ & Datastream \\
\hline
\end{tabular}

Continued 


\begin{tabular}{|c|c|c|}
\hline $\begin{array}{l}\text { Natural Logarithm of } \\
\text { the Deal Value for Non- } \\
\text { Earnout Financed } \\
\text { Transactions and the } \\
\text { Initial Payments in } \\
\text { Earnout Financed } \\
\text { Transactions, Divided } \\
\text { by The target's Profits } \\
\text { Before Taxes } \\
\text { (INITIALDV) }\end{array}$ & $\begin{array}{l}\text { A continuous variable that is equal to the deal value when an } \\
\text { earnout is not included and equal only to the initial payment when } \\
\text { the earnout is included, divided by the target's pre-acquisition } \\
\text { profitability. This variable is appropriately defined in Section } 3 \text {. }\end{array}$ & SDC \\
\hline $\begin{array}{l}\text { Percentage of the Deal } \\
\text { Payment Financed With } \\
\text { Stocks (STOCK_PERC) }\end{array}$ & The percentage of the total transaction value financed with stocks. & SDC \\
\hline $\begin{array}{r}\text { Positive Profits Before } \\
\text { Taxes } \\
\text { (POSPBT) }\end{array}$ & $\begin{array}{l}\text { The audited value of the profit-before taxes of the target for the } \\
\text { financial year preceding the acquisition. As this measure is used in } \\
\text { calculating acquisition multiples, we only include transaction in } \\
\text { which this measure has a positive value. }\end{array}$ & Nexis-UK + InvestEgate \\
\hline $\begin{array}{r}\text { Premium Offered to the } \\
\text { Target } \\
\text { (PREMIUM) }\end{array}$ & $\begin{array}{l}\text { The ratio of the deal value to the target's pre-acquisition } \\
\text { profitability }\end{array}$ & $\mathrm{SDC}+$ Nexis-UK + InvestEgate \\
\hline $\begin{array}{r}\text { Propensity Score } \\
\text { (PROP_SCORE) }\end{array}$ & The propensity scores estimated by the Logistic model in Table 3 & SDC + Nexis-UK + InvestEgate \\
\hline $\begin{array}{r}\text { Relative Size of the Deal } \\
\text { (RS) }\end{array}$ & Ratio of (DV) to (MV). & Datastream + SDC \\
\hline $\begin{array}{r}\text { Relative Earnout } \\
\text { Payment Size } \\
\text { (REAS) }\end{array}$ & $\begin{array}{l}\text { The ratio of the maximum size of the deferred payment to overall } \\
\text { deal value which covers both the initial payment and the } \\
\text { maximum value of the deferred payment }\end{array}$ & SDC \\
\hline $\begin{array}{r}\text { Stock Financed } \\
\text { Acquisitions (STOCK) }\end{array}$ & $\begin{array}{l}\text { Dummy }=1 \text { when the consideration is } 100 \% \text { financed with stocks } \\
\text { and } 0 \text { otherwise. }\end{array}$ & SDC \\
\hline $\begin{array}{r}\text { Transactions financed } \\
\text { With a Mix of Cash and } \\
\text { Stocks Without an } \\
\text { Earnout } \\
\text { (MIXED) }\end{array}$ & $\begin{array}{l}\text { Dummy = } 1 \text { when the deal is financed with a mix of cash and stock } \\
\text { excluding earnout and } 0 \text { otherwise. }\end{array}$ & SDC \\
\hline
\end{tabular}


Table 1: Annual distribution of our sampled deals

\begin{tabular}{|c|c|c|c|c|c|c|c|c|c|c|c|c|c|c|c|c|c|c|c|}
\hline \multirow[b]{2}{*}{ YEAR } & \multicolumn{7}{|c|}{ Panel A } & \multicolumn{12}{|c|}{ Panel B } \\
\hline & ALL & CASH & STOCK & MIXED & EA & $\begin{array}{l}\text { FULL } \\
\end{array}$ & CBA & IND & HCR & CST & MAT & MED & RTL & CPS & HT & EPW & TLC & FIN & $\begin{array}{l}\text { RST } \\
\end{array}$ \\
\hline 1996 & 29 & 9 & 0 & 4 & 16 & 28 & 4 & 10 & 0 & 4 & 4 & 1 & 0 & 1 & 6 & 0 & 2 & 0 & 1 \\
\hline 1997 & 38 & 8 & 4 & 2 & 24 & 37 & 14 & 12 & 1 & 3 & 2 & 3 & 1 & 7 & 6 & 0 & 1 & 1 & 1 \\
\hline 1998 & 37 & 10 & 0 & 6 & 21 & 37 & 11 & 8 & 0 & 0 & 4 & 2 & 3 & 12 & 7 & 0 & 0 & 1 & 0 \\
\hline 1999 & 35 & 7 & 2 & 3 & 23 & 35 & 7 & 5 & 0 & 3 & 6 & 2 & 2 & 5 & 10 & 0 & 0 & 2 & 0 \\
\hline 2000 & 35 & 10 & 0 & 2 & 23 & 35 & 12 & 3 & 1 & 1 & 3 & 4 & 1 & 10 & 11 & 0 & 1 & 0 & 0 \\
\hline 2001 & 28 & 2 & 0 & 0 & 26 & 28 & 4 & 1 & 0 & 2 & 0 & 3 & 0 & 10 & 9 & 0 & 1 & 2 & 0 \\
\hline 2002 & 12 & 1 & 0 & 0 & 11 & 12 & 2 & 2 & 1 & 0 & 0 & 2 & 0 & 3 & 1 & 0 & 1 & 2 & 0 \\
\hline 2003 & 11 & 1 & 0 & 1 & 9 & 10 & 2 & 3 & 1 & 0 & 0 & 4 & 0 & 1 & 2 & 0 & 0 & 0 & 0 \\
\hline 2004 & 18 & 1 & 0 & 2 & 15 & 18 & 2 & 1 & 0 & 1 & 0 & 6 & 0 & 4 & 3 & 0 & 1 & 1 & 1 \\
\hline 2005 & 34 & 3 & 0 & 1 & 30 & 33 & 5 & 7 & 6 & 1 & 0 & 2 & 1 & 8 & 5 & 0 & 1 & 3 & 0 \\
\hline 2006 & 32 & 2 & 0 & 3 & 27 & 31 & 6 & 6 & 1 & 0 & 0 & 2 & 1 & 11 & 10 & 0 & 0 & 1 & 0 \\
\hline 2007 & 40 & 2 & 1 & 2 & 35 & 40 & 6 & 6 & 1 & 1 & 2 & 4 & 0 & 11 & 9 & 1 & 1 & 4 & 0 \\
\hline 2008 & 22 & 8 & 0 & 0 & 14 & 22 & 8 & 2 & 1 & 1 & 1 & 1 & 1 & 8 & 4 & 0 & 0 & 3 & 0 \\
\hline 2009 & 18 & 5 & 0 & 6 & 7 & 18 & 7 & 2 & 0 & 0 & 1 & 2 & 2 & 5 & 3 & 0 & 1 & 1 & 1 \\
\hline 2010 & 35 & 11 & 1 & 5 & 18 & 30 & 12 & 6 & 1 & 0 & 0 & 4 & 2 & 8 & 8 & 2 & 3 & 1 & 0 \\
\hline$N$ & 424 & 80 & 8 & 37 & 299 & 414 & 102 & $74(50)$ & $14(12)$ & $17(9)$ & $23(5)$ & $42(37)$ & $14(6)$ & $104(72)$ & $94(77)$ & $3(2)$ & $13(10)$ & $22(18)$ & $4(1)$ \\
\hline$\%$ & 100 & 18.87 & 1.89 & 8.73 & 70.52 & 97.64 & 24.06 & 17.45 & 3.30 & 4.01 & 5.42 & 9.91 & 3.30 & 24.53 & 22.17 & 0.71 & 3.07 & 5.19 & 0.94 \\
\hline
\end{tabular}

Note: Panel A represents the annual distribution of private target M\&A bids announced by UK public acquirers between January $1^{\text {st }}, 1996$ and December $31^{\text {st }}$, 2010 . The distribution of the sample is presented according to the total number of transactions (ALL), method of payment (earnout-financing (EA) or single-payments settled in cash (CASH), stock (STOCK) or mixes of both (MIXED)), whether the acquisition is classified by SDC as a full acquisition (FULL), in which case the acquirer controls $100 \%$ of the target once the acquisition becomes effective, and whether the acquisition is classified by SDC as a cross-border transaction (CBA) whereby the target is not registered as a UK company. Panel B represents the yearly distribution of private target M\&A bids with respect to the target's sector. The (HT), Energy and Power (EPW), Telecommunications (TLC), Financials (FIN) and Real Estate (RST). In Panel B and row N, the number in parentheses refers to the number of earnout financed deals in each target sector. 
Table 2: Summary statistics

\begin{tabular}{|c|c|c|c|c|c|c|c|c|c|c|c|c|}
\hline & \multicolumn{2}{|c|}{$\mathrm{MV}(\mathrm{Em})$} & \multicolumn{2}{|c|}{ ACQ_MTBV } & \multicolumn{2}{|c|}{$\mathrm{DV}(£ \mathrm{~m})$} & \multicolumn{2}{|c|}{ AGE (days) } & \multicolumn{2}{|c|}{ STOCK_PERC (\%) } & \multicolumn{2}{|c|}{$\mathrm{RS}$} \\
\hline & Mean & Med. & Mean & Med. & Mean & Med. & Mean & Med. & Mean & Med. & Mean & Med. \\
\hline ALL & 294 & 71 & 4 & 2 & 13 & 6 & 4,833 & 3,398 & 12.35 & 0.0 & 0.48 & 0.08 \\
\hline $\mathrm{CASH}$ & 323 & 92 & 3 & 2 & 13 & 4 & 6,451 & 5,323 & 0.00 & 0.0 & 0.17 & 0.05 \\
\hline STOCK & 228 & 48 & 8 & 2 & 46 & 7 & 1,685 & 1,140 & 100 & 100.0 & 11.88 & 0.11 \\
\hline MIXED & 409 & 51 & 4 & 2 & 9 & 5 & 5,968 & 4,501 & 33.6 & 29.3 & 0.24 & 0.09 \\
\hline EA & 274 & 70 & 4 & 2 & 12 & 6 & 4,343 & 2,562 & 10.6 & 0.0 & 0.29 & 0.09 \\
\hline NEA & 342 & 77 & 4 & 2 & 14 & 4 & 6,003 & 4,501 & 16.3 & 0.0 & 0.94 & 0.05 \\
\hline DOM & 227 & 62 & 4 & 2 & 11 & 5 & 4,152 & 2,284 & 12.5 & 0.0 & 0.54 & 0.08 \\
\hline \multirow[t]{3}{*}{ CBA } & 505 & 146 & 4 & 3 & 30 & 20 & 6,982 & 5,780 & 11.6 & 0.0 & 0.3 & 0.07 \\
\hline & \multicolumn{2}{|c|}{ CULT_IND } & \multicolumn{2}{|c|}{ POSPBT $(£ m)$} & \multicolumn{2}{|c|}{ PREMIUM } & \multicolumn{2}{|c|}{ EASIZE $(£ m)$} & \multicolumn{2}{|c|}{ REAS } & \multicolumn{2}{|c|}{ LENGTH (months) } \\
\hline & Mean & Med. & Mean & Med. & Mean & Med. & Mean & Med. & Mean & Med. & Mean & Med. \\
\hline ALL & 1.3 & 1 & 1.68 & 0.5 & 35.09 & 10.87 & - & - & - & - & - & - \\
\hline $\mathrm{CASH}$ & 1.8 & 1 & 3.61 & 0.48 & 15.58 & 7.75 & - & - & - & - & - & - \\
\hline STOCK & 1.8 & 1 & 1.11 & 0.30 & 126.05 & 17.25 & - & - & - & - & - & - \\
\hline MIXED & 1.6 & 1 & 1.04 & 0.54 & 23.87 & 10.14 & - & - & - & - & - & - \\
\hline EA & 1.2 & 1 & 1.26 & 0.50 & 39.27 & 11.75 & 4.8 & 2.3 & 0.36 & 0.32 & 19.8 & 19 \\
\hline NEA & 1.7 & 1 & 2.69 & 0.49 & 25.11 & 8.82 & - & - & 0.00 & 0.00 & 0.00 & 0.00 \\
\hline DOM & 1.0 & 1 & 1.02 & 0.44 & 37.8 & 10.96 & 3.8 & 1.9 & 0.38 & 0.33 & 10.7 & 1 \\
\hline CBA & 2.4 & 1 & 3.78 & 0.90 & 26.56 & 10.17 & 9.3 & 4.7 & 0.29 & 0.25 & 15.1 & 12 \\
\hline
\end{tabular}

Note: This Table represents the mean and median values of a set of continuous covariates in the sample. The covariates are the acquirer's market value (MV), the acquirer's market-to-book value (ACQ_MTBV), the transaction value (DV) and the bidder's age (AGE). The table also includes the means and medians of the portion of the transaction financed with stocks (STOCK PERC), the size of deal payment relative to the acquirer's market value (RS), the Culture Index (CULT_IND) defined in Appendix 1, the target's positive Profits-before-Taxes (POSPBT), the premium measured by the variable (PREMIUM) defined in Appendix 1, the size of the deferred payment in earnout financed deals (EASIZE), the relative earnout size (REAS) and the length of earnout period (LENGTH). These measures are reported for the sample covering all the transactions (ALL), the transactions fully financed with cash (CASH), the transactions fully financed with stocks (STOCK), the transactions fully financed with a mix of cash and stock with no inclusion of earnouts (MIXED), the transactions financed with earnouts (EA) and the general group of transactions not financed with earnouts (NEA). The table also presents the means and medians of these variables based on the geographic scope of the transaction (domestic transactions (DOM) and cross-borders transactions (CBA). Please refer to Appendix1 for an accurate description of the variables. 
Table 3: Matching analysis

\begin{tabular}{|c|c|c|c|c|c|c|c|c|}
\hline \multicolumn{9}{|l|}{ Panel A } \\
\hline Intercept & $\ln (\mathrm{MV})$ & $\ln (\mathrm{AGE})$ & FREQ & STOCK_PERC & CULT_IND & $\mathrm{CBA}$ & DUMMYRS & POSPBT \\
\hline 1.783* & $0.247^{* *}$ & $-0.229^{* *}$ & $0.589^{*}$ & $-0.012^{* *}$ & $-0.302^{* *}$ & $-0.642^{*}$ & $1.037^{* * *}$ & $-0.013^{*}$ \\
\hline$(0.976)$ & $(0.104)$ & $(0.105)$ & $(0.324)$ & $(0.005)$ & $(0.128)$ & $(0.337)$ & $(0.284)$ & $(0.007)$ \\
\hline \multicolumn{9}{|l|}{ Panel B } \\
\hline & \multicolumn{4}{|c|}{ Before Matching } & \multicolumn{4}{|c|}{ After Matching } \\
\hline & $\begin{array}{c}\text { Treated } \\
\text { Group }\end{array}$ & \multicolumn{2}{|c|}{$\begin{array}{c}\text { Control } \\
\text { Group }\end{array}$} & $p$-value & $\begin{array}{c}\text { Treated } \\
\text { Group }\end{array}$ & \multicolumn{2}{|c|}{$\begin{array}{c}\text { Control } \\
\text { Group }\end{array}$} & $p$-value \\
\hline PROP_SCORE & 0.74 & \multicolumn{2}{|c|}{0.60} & 0.01 & 0.74 & \multicolumn{2}{|r|}{0.75} & 0.75 \\
\hline STOCK_PERC & 10.67 & \multicolumn{2}{|c|}{16.35} & 0.05 & 10.54 & \multicolumn{2}{|r|}{10.19} & 0.81 \\
\hline CULT_IND & 1.18 & \multicolumn{2}{|c|}{1.75} & 0.00 & 1.17 & \multicolumn{2}{|r|}{1.18} & 0.86 \\
\hline CBA & 0.18 & \multicolumn{2}{|c|}{0.38} & 0.00 & 0.18 & \multicolumn{2}{|r|}{0.18} & 0.90 \\
\hline AGE & 4343.80 & \multicolumn{2}{|c|}{6003.70} & 0.00 & 4396.10 & \multicolumn{2}{|c|}{4731.70} & 0.27 \\
\hline FREQ & 0.27 & \multicolumn{2}{|c|}{0.16} & 0.01 & 0.26 & \multicolumn{2}{|r|}{0.22} & 0.13 \\
\hline MV & 274 & \multicolumn{2}{|c|}{342} & 0.48 & 274 & \multicolumn{2}{|r|}{266} & 0.93 \\
\hline POSPBT & 1.26 & \multicolumn{2}{|c|}{2.69} & 0.20 & 1.26 & \multicolumn{2}{|r|}{3.18} & 0.15 \\
\hline DUMMYRS & 0.54 & \multicolumn{2}{|c|}{0.04} & 0.01 & 0.54 & \multicolumn{2}{|r|}{0.57} & 0.40 \\
\hline
\end{tabular}

Note: Panel A presents the Logistic model that is used in estimating the propensity scores. The dependent variable (EA) is assigned the value of 1 if an earnout is included in the deal's financing process, and 0 otherwise. The independent variables are: the natural logarithms of the acquirer's market value $(\ln (\mathrm{MV}))$ and age $(\ln (\mathrm{AGE}))$, the presence of a frequent acquirer (FREQ), the percentage of total deal value that is financed with stocks (STOCK_PERC), the Culture Index (CULT_IND), the presence of a foreign target (CBA), the presence of relatively large target (DUMMYRS), and the target's pre-acquisitions positive PBT (POSPBT). Panel B reports the outcome of the matching exercise with caliper 0.25 . After the matching, the treated and control groups contain, respectively, to earnout financed (EA) and non-earnout financed (NEA) deals on the matched sample of 386 observations. For each of the covariates, we report the mean in the treated and control group before and after the matching. The Absolute Standardized Mean Difference refers to the absolute value of the ratio of the difference between the mean of the variable in the treated group and the mean of this variable in the control group, divided by the square root of the mean of the covariate's variances in both groups. Please refer to Appendix 1 for an accurate description of the variables. 
Table 4: Determinants of the takeover premium

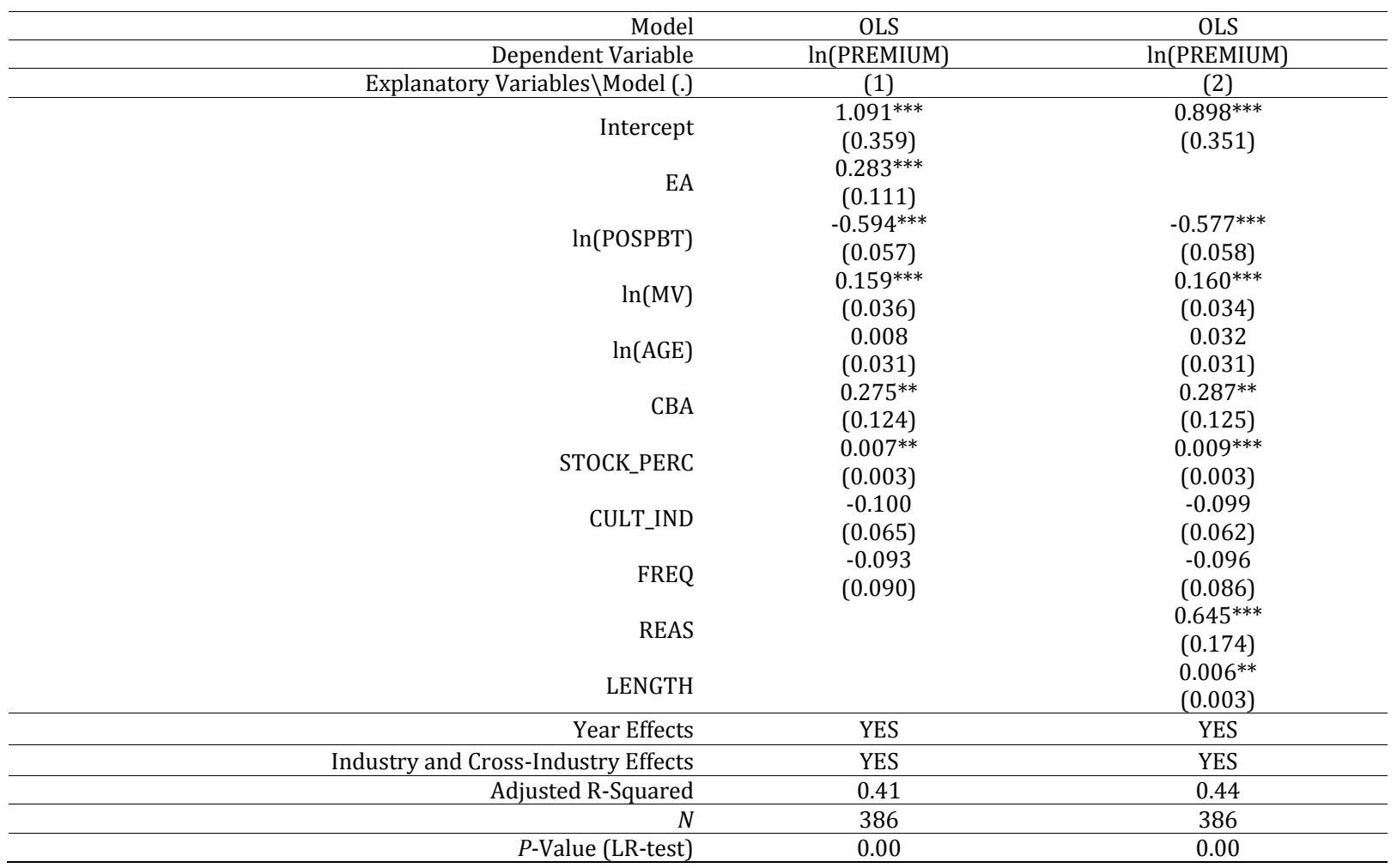

Note: This table represents two models that explain the variation in the premium offered to the private target's owners. The first model puts emphasis on the impact of the presence of earnout financing on the premium while the second model's emphasis is on the impact of the earnout contract's terms on this premium. The standard errors reported in parentheses are corrected for heteroskedasticity using the White (1980) heteroskedasticity consistent standard errors. Variables not included in this table were not found to have significant effects. ${ }^{* * *}, * *$, and ${ }^{*}$ represent significance at the $1 \%, 5 \%$ and $10 \%$ levels respectively. Please refer to Appendix 1 for an accurate description of the variables. 
Table 5: Multivariate analysis of the earnout's structure

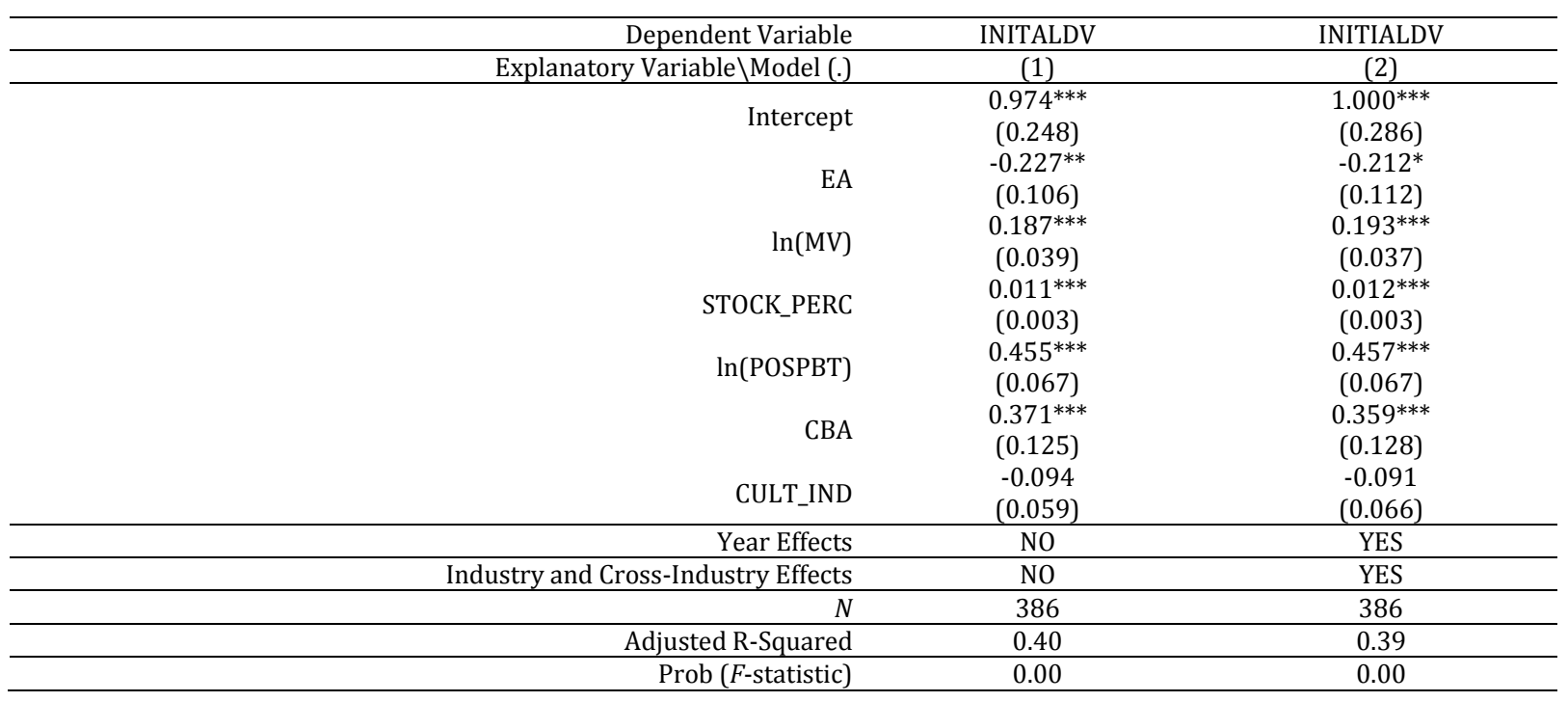

Note: This table reports the results of the cross-sectional analysis explaining the relationship between the initial payments in earnout financed deals and the deal payments in non-earnout financed deals. The dependent variable is INITIALDV is defined in Section 3.The standard errors reported in parentheses are corrected for heteroskedasticity using the White (1980) heteroskedasticity consistent standard errors. Variables not included in this table were not found to have significant effects. ${ }^{* * *}, * *$, and ${ }^{*}$ represent significance at the $1 \%, 5 \%$ and $10 \%$ levels respectively. Please refer to Appendix 1 for an accurate description of the variables. 
Table 6: Determinants of the announcement period abnormal returns

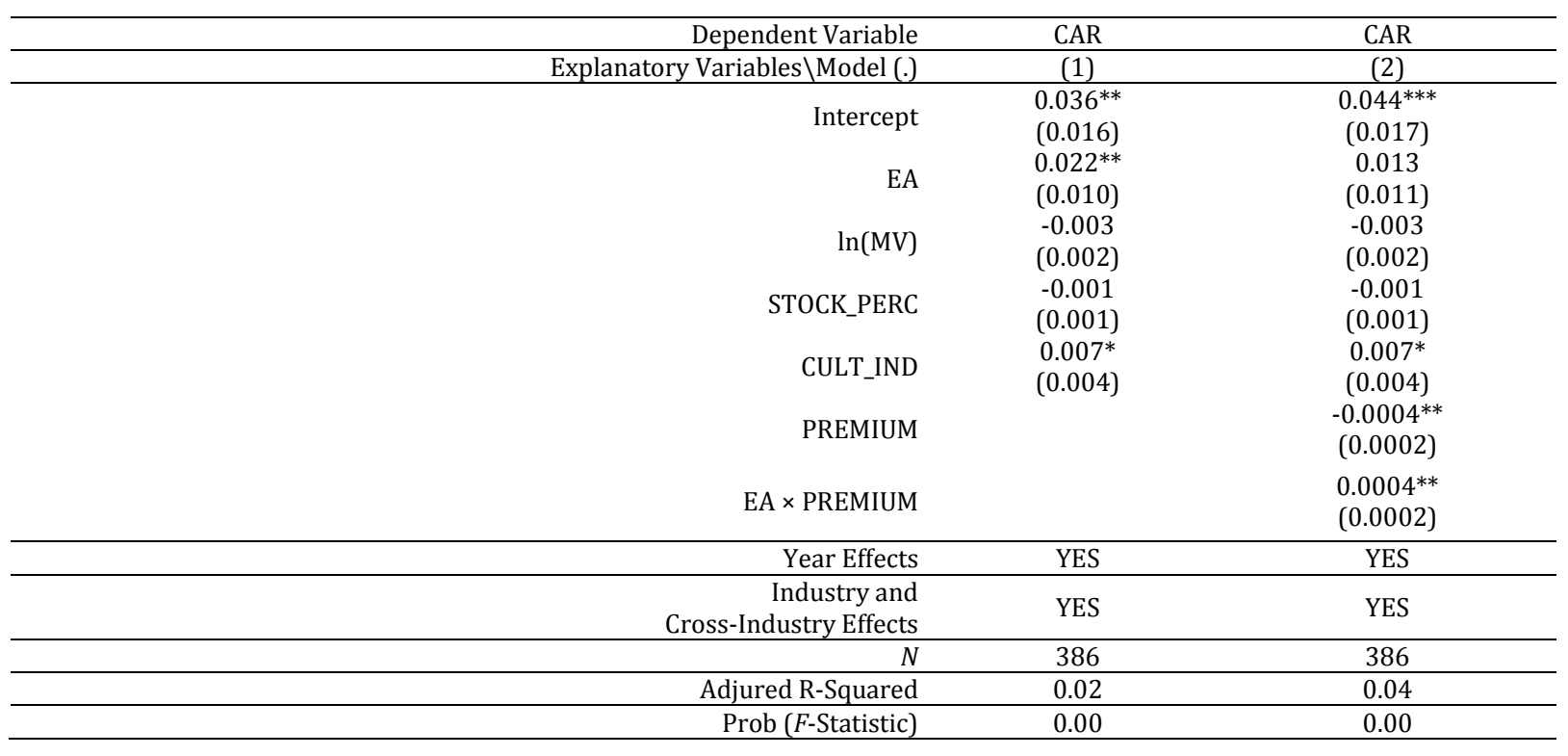

Note: This table represents the cross-sectional analysis of the public UK acquirers' CAR in the 5-day period $(-2,2)$ surrounding the acquisition announcement. Model 1 examines the determinants of CAR without introducing the interaction of the premium (PREMIUM) with the presence of earnouts (EA). Model 2 examines whether the different interpretations by the market of the acquisition premia explains the positive market reaction to the presence of earnouts. The standard errors reported in parentheses are corrected for heteroskedasticity using White's (1980) heteroskedasticity consistent standard errors. Variables not included in this table were included in alternative specifications and were not found to have significant effects. ${ }^{* * *}, * *$, and ${ }^{*}$ represent significance at the $1 \%, 5 \%$ and $10 \%$ levels respectively. Please refer to Appendix 1 for an accurate description of the variables. 
Table 7: Treatment effect estimates and sensitivity analysis

\begin{tabular}{|c|c|c|}
\hline Outcome & $\ln ($ PREMIUM) & INITIALDV \\
\hline $\begin{array}{r}A T T \\
\text { (Abadie and Imbens (2006) Standard Errors) }\end{array}$ & $\begin{array}{c}47.25^{* * *} \\
(0.07)\end{array}$ & $\begin{array}{l}-11.03 \\
(9.92)\end{array}$ \\
\hline Cut-off $\Gamma$ value $(\mathrm{p} \approx 0.05)$ & 2.00 & 1.50 \\
\hline Cut-off $\Gamma$ value $(p \approx 0.10)$ & 2.20 & 1.41 \\
\hline
\end{tabular}

Note: This table represents the outcome of the matching and the Rosenbaum (2002) sensitivity analyses. For both variables, $\ln$ (PREMIUM) and INITIALDV, we estimate the Average Treatment Effect on the Treated (ATT) with the Abadie and Imbens (2006) standard errors after a 1:1 matching exercise with caliper 0.1 . We also present the cut-off $\Gamma$ levels at which the treatment effects become significant at the $5 \%$ and $10 \%$ levels for $\ln \left(\right.$ PREMIUM) and insignificant for INITIALDV. ${ }^{* *},{ }^{* *}$, and ${ }^{*}$ represent significance at the $1 \%, 5 \%$ and $10 \%$ levels respectively. 